\title{
UZAKTAN ALGILAMA GÖRÜNTÜLERINDEN TARIMSAL KURAKLIĞIN BELIRLENMESİ
}

\author{
Ali Levent Yağcl \\ Dr., İzmir Kâtip Çelebi Üniversitesi, Mühendislik ve Mimarlık Fakültesi, Harita Mühendiliği Bölümü, 35620, Çiğli, İzmir, \\ alilevent.yagci@ikc.edu.tr
}

\section{ÖZET}

Tarımsal kuraklık belirli zaman aralıklarında tekrarlayan bir dogal afettir ve global tarıma, gıda güvenliğine ve ekonomiye ciddi bir tehdit oluşturmaktadır. Uzaktan algılama teknolojisi son yıllarda uzaydan tarımsal kurakliğın belirlenmesinde popüler bir araç olmuştur. Tarımsal kuraklı̆̆ın belirlenmesi, yersel bitki sağlık durumlarının analizi ile gerçekleştirilmektedir. Normalize edilmiş bitki indeksi (Normalized Difference Vegetation Index; NDVI), yüksek biyokütkleye (biomass) sahip bitki örtüsü bölgelerdeki zaafina rağmen, bitki örtüsünün sağllk durumunu ölçen bitki indekleri içinde en çok kullanılanıdır. Bu çalışmada, uzaktan algllama verisinden hesaplanan bitki indeklerinin, tarımsal kuralı̆̆ın belirlenmesindeki potensiyeli gösterilecektir. Türkiye'nin Ege Bölgesi ve Amerika Birleşik Devletleri'nde (ABD) yapılan ön analiz sonuçları bu özette sunulacaktır.

Anahtar Sözcükler: MODIS, NDVI, tarımsal kuraklık

\section{ABSTRACT}

\section{AGRICULTURAL DROUGHT MONITORING FROM REMOTELY-SENSED IMAGES}

\begin{abstract}
Agricultural drought is a major recurring natural disaster, which often poses a serious threat to global agriculture, food security, and economy. Satellite remote sensing has become a popular tool to identify agricultural drought through analysis of terrestrial vegetation health conditions. Of the vegetation indices, Normalized Difference Vegetation index is a leading index to monitor terrestrial vegetation conditions despite its shortcomings at high biomass regions. In this study, the potential of remotely-sensed vegetation indices in monitoring agricultural drought conditions will be demonstrated. The results of preliminary analysis carried out in Aegean region of Turkey and USA will be presented in this paper.
\end{abstract}

Keywords:, MODIS, NDVI, agricultural drought

\section{GíRIS}

Kuraklık belirli sıklıklarla tekrarlayan bir doğal afettir ve iklim değişkenliğinin kaçınılmaz bir doğal sonucudur. Genelde, kuraklık tarımsal üretimin sekteye uğramasına ve su kaynaklarında azalmaya yol açar. Böylelikle, hem direk olarak hem de dolaylı yoldan ekonomiye negatif bir etkide bulunur.

Kuraklık, Amerikan Meteoroloji Birliği (American Meteorological Society; AMS) tarafından 4 genel başlıkla sınıflandırılmıştır: meteorolojik, tarımsal, hidrolojik ve sosyoekonomik (American Meteorological Society 2013). İlk üç kuraklık tipi fiziksel, hidrometeorolojik ve biolojik parametreler ile tanımlanmasına karşın, dördüncüsü kuraklığın topluma etki etmesiyle ilgilidir. Bu çalışmanın konusu olan tarımsal kuraklık, yağış miktarının mevsim normallerinin altına düşmesinin hemen ardından görülen yüksek su kaybı (terleme ve buharlaşma yoluyla) ve düşük toprak neminin, bitki örtüsü ve tarım ürünlerinin durumuna olumsuz etki etmesi olarak tanımlanır. Kuraklığın, 'şiddet', 'süre' (başlangıç ve bitiş arasında geçen süre) ve 'mekânsal kapsam' gibi 3 tane karakter özellikleri vardır (Wilhite 2000). Bunlar kuraklık harita veya sonuçlarında mutlaka olması gereken unsurlardır.

Uzaktan algılama teknolojisi, yersel istasyonlarda toplanan meteorolojik verilerden elde edilen geleneksel kuraklık belirleme yöntemlerine göre bazı avantajlar barındırmaktadır. Bu avantajlar uzaktan algılama sensörlerinin bitki örtüsü durumunu günlük olarak raporlaması ve yeryüzünün heryerinde günlük örnekleme yapmasıdır. Tarımsal kuraklık, tanımda da belirtildiği gibi, büyük ölçekte bitki örtüsünün sağlık durumunu olumsuz olarak etkilenmesidir ve uzaktan algılama verilerinden elde edilen bitki indekleri bitkilerin durumunu izlemek için kullanılmaktadır. Ayrıca, uyduların yeryüzünün her kısmında örnekleme yapması, kuraklığın mekânsal kapsamının belirlenmesi için birebirdir. Bundan dolayı, son yıllarda uzaktan algılama teknolojisi tarımsal kuraklığın belirlenmesinde popüler bir araç olmuştur.

Uzaktan algılama yoluyla tarımsal kuraklık belirlemenin öncü uygulamaları Advanced Very High Resolution Radiometer (AVHRR) adlı sensör verisinin kullanılması ile başlamıştır (Kogan 1993). Bu uygulamalardan sonra AVHRR sensörünün bazı dezavantajları nedeniyle, tarımsal kuraklık çalışmaları Aqua ve Terra uydularının üzerinde bulunan Moderate Resolution Imaging Spectroradiometer (MODIS) sensörü ile toplanan veriler ile hız kazanmıştır. 
$\mathrm{Bu}$ çalışmada MODIS uydu verisinden elde edilen bitki örtüsü ve kuraklık indisleri ile tarımsal kuraklığın belirlenmesi için kullanılacaktır. Çalışma alanı olarak, Türkiye'nin Ege Bölgesi ve Amerika Birleşik Devletleri (ABD) seçilmiştir.

\subsection{Kullanılan Veriler}

$\mathrm{Bu}$ çalışmada kullanılan uygu görüntüleri Terra uydusunun üzerine monte edilmiş "the Moderate Resolution Imaging Spectroradiometer" (MODIS) tarafından toplanmıştır. Bu kullanılan MODIS uydu görüntülerinin kodu MOD13A2 olarak adlandırılmıştır. 2000-2018 yılları arasındaki görüntüler The Land Processes Distributed Active Archive Center'ın websitesinden (LP DAAC; https://lpdaac.usgs.gov/) indirilmiştir. Bu 16 günlük komposit görüntülerin mekânsal çözünürlüğü $1 \mathrm{~km}$ 'dir. Uydu görüntüleri ile gelen kalite kontrol katmanlarına bakılarak bulutlu ve düşük kalitedeki gözlemler kuraklık indeksi hesaplamasından çıkarılmıştır. Bu aşama çok önemli bir aşamadır ve mutlaka kuraklık indeksi çalışmalarında göz önünde bulundurulmalıdır.

\section{2 Çalışmada Kullanılan İndeksler}

$\mathrm{Bu}$ çalışmada, bitki örtüsünün durumunu göstermesi Normalize edilmiş bitki indeksi (Normalized Difference Vegetation Index; NDVI) ve tarımsal kuralığın belirlenmesi için de Bitki Durumu İndeksi (Vegetation Condition Index; VCI) kullanılmıştır. NDVI sadece bitki örtüsünün durumunu gösterdiği için, tarımsal kuraklığın belirlenmesi için tek başına yeterli değildir ve bu yüzden NDVI-tabanlı VCI kuraklık indeksi geliştirilmiştir (Kogan 1993). Bu indis dünyanın birçok yerinde gerçekleştirilen çalışamalarda tarımsal kuraklığı başarılı bir şekilde saptamış ve haritalamıştır (Deng et al. 2013; Yagci et al. 2012; Yagci et al. 2011; Kogan 1995). NDVI ve VCI sırasıyla aşağıda gösterilen denklem 1 ve 2 ile hesaplanır.

$$
\begin{aligned}
N D V I & =\frac{N I R-R E D}{\mathrm{NIR}+\mathrm{RED}} \\
V C I_{i j} & =\frac{N D V I_{i j}-N D V I_{\text {min }}}{N D V I_{\text {max }}+N D V I_{\text {min }}} \times 100
\end{aligned}
$$

Denklem 1 ile hesaplanan kuraklık indeksi değerleri aşağıda Çizelge 1'de verilen gözlenen kuralığın şiddetine göre farklı kategoriler altında sınıflandırılır. İstinai kuraklık en şiddetli kuraklık ve anormal kuraklık ise en düşük şiddetli kuraklık biçimidir. Bu sınıflandırma Amerika Birleşik Devletleri'nde bulunan (ABD) yarı-resmi Amerikan Kuraklık İzleme Dairesi'nin (United States Drought Monitor, USDM) önerdiği yüzdelik dilimlerden oluşturulmuştur (Svoboda et al. 2002; The National Drought Mitigation Center 2016).

Çizelge 1 - Kuraklık haritaları oluşturulurken kullanılan kuraklık sınıflandırması.

\begin{tabular}{|l|l|}
\hline VCI Değeri & Kuraklık Sınıfı \\
\hline $0-2$ & İstisnai Kurak \\
\hline $3-5$ & Aşırı Kurak \\
\hline $6-10$ & Şiddetli Kurak \\
\hline $11-20$ & Orta Kurak \\
\hline $21-30$ & Anormal Kuruk \\
\hline $31-100$ & Normal \\
\hline
\end{tabular}

\section{DEĞERLENDİRME}

VCI kuraklık indeksinden elde edilen tarımsal kuraklık bilgisinin doğrulama çalışmaları, Türkiye ve Amerika Birleşik Devletleri'nde (ABD) yapılmıştır. Ayrıca Türkiye'nin Ege Bölgesindeki çalışmada, kuraklık haritaları üzüm verimi (Şekil 1) ile ABD'deki çalışmada ise yarı-resmî Amerikan Kuraklık İzleme Dairesi'nin (United States Drought Monitor, USDM) sonuçlarıyla karşılaştırılmıştır. 2007 ve 2009 yıllarında Türkiye genel kuraklık haritası 26 Haziran - 11 Temmuz tarih aralığı için Şekil 2'de ve 12 Temmuz - 27 Temmuz aralığ içim Şekil 3'de verilmiştir. Bu haritanın Ege Bölgesi üzerine yakınlaştırılmış kuraklık haritası Şekil 4'te ve ABD sonuçları ise Şekil 5'te betimlenmiştir. Buna göre, 2007 yılında Türkiye'nin batı ve iç kısımlarında şiddetli kuraklık olduğu görülmüştür. Buna paralel 2007 yılında Ege Bölgesi'nde üzüm verimi 10 yıllık bir aralığın en düşük değerini almıştır. 2009 yılında ise herhangi kuraklık durumu görülmemiştir. Aynı şekilde Eğe Bölgesi'nin üzüm rekoltesinde herhangi bir düşüş görülmemiştir. Şekil 4'teki Ege bölgesi kuraklık haritasında bölgenin batı kısmında yoğunlaşan bir kuraklık 
A.L.Yağcı: Uzaktan Algılama Görüntülerinden Tarımsal Kuraklığın Belirlenmesi

olduğu gözlemlenmiştir (Şekil 4). Ayrıca, VCI-tabanlı kuraklık haritası USDM kuraklık haritası ile görsel olarak çok iyi çakışmaktadır (Şekil 5).

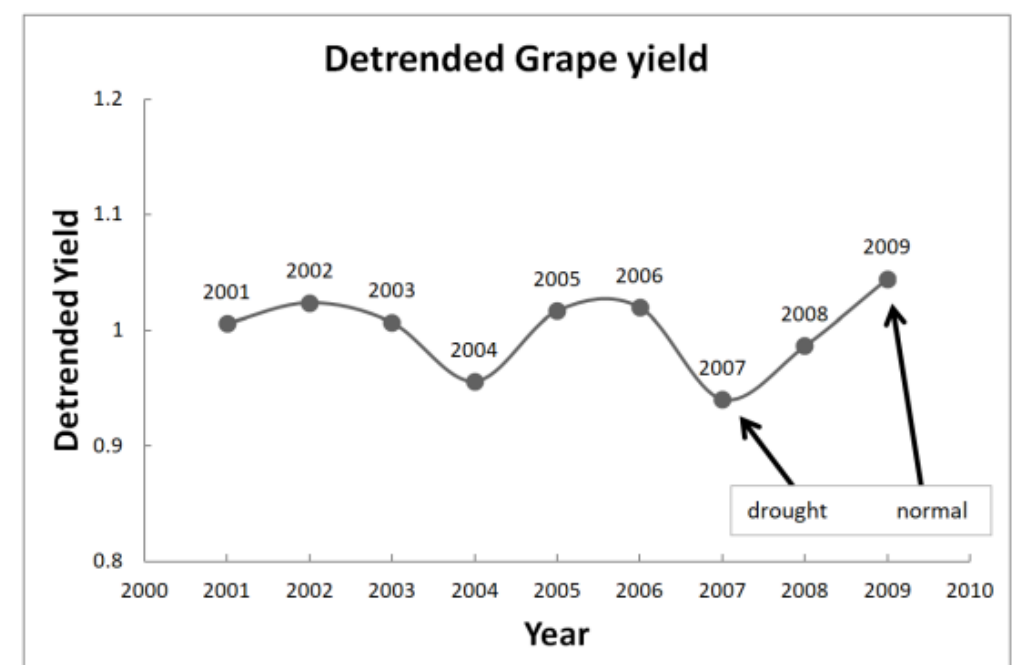

Şekil 1. 2001-2009 yılları arasındaki Türkiye Ege Bölgesi'ndeki trendden arındırılmış üzüm verimi (Yagci et al. 2011).

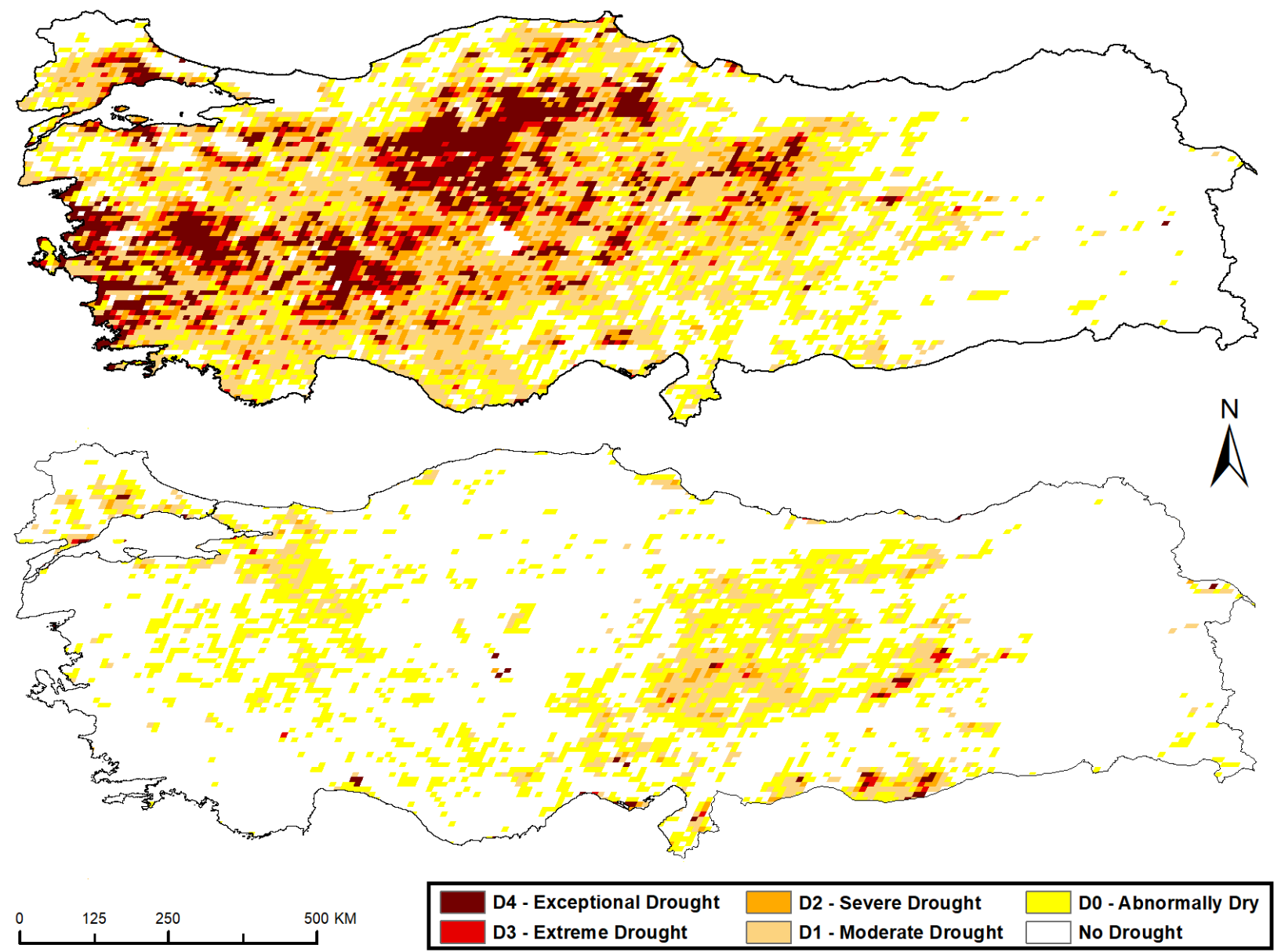

Şekil 2. 26 Haziran - 11 Temmuz tarih aralığı için 2007 ve 2009 yılları Türkiye Kuraklık Haritaları. 


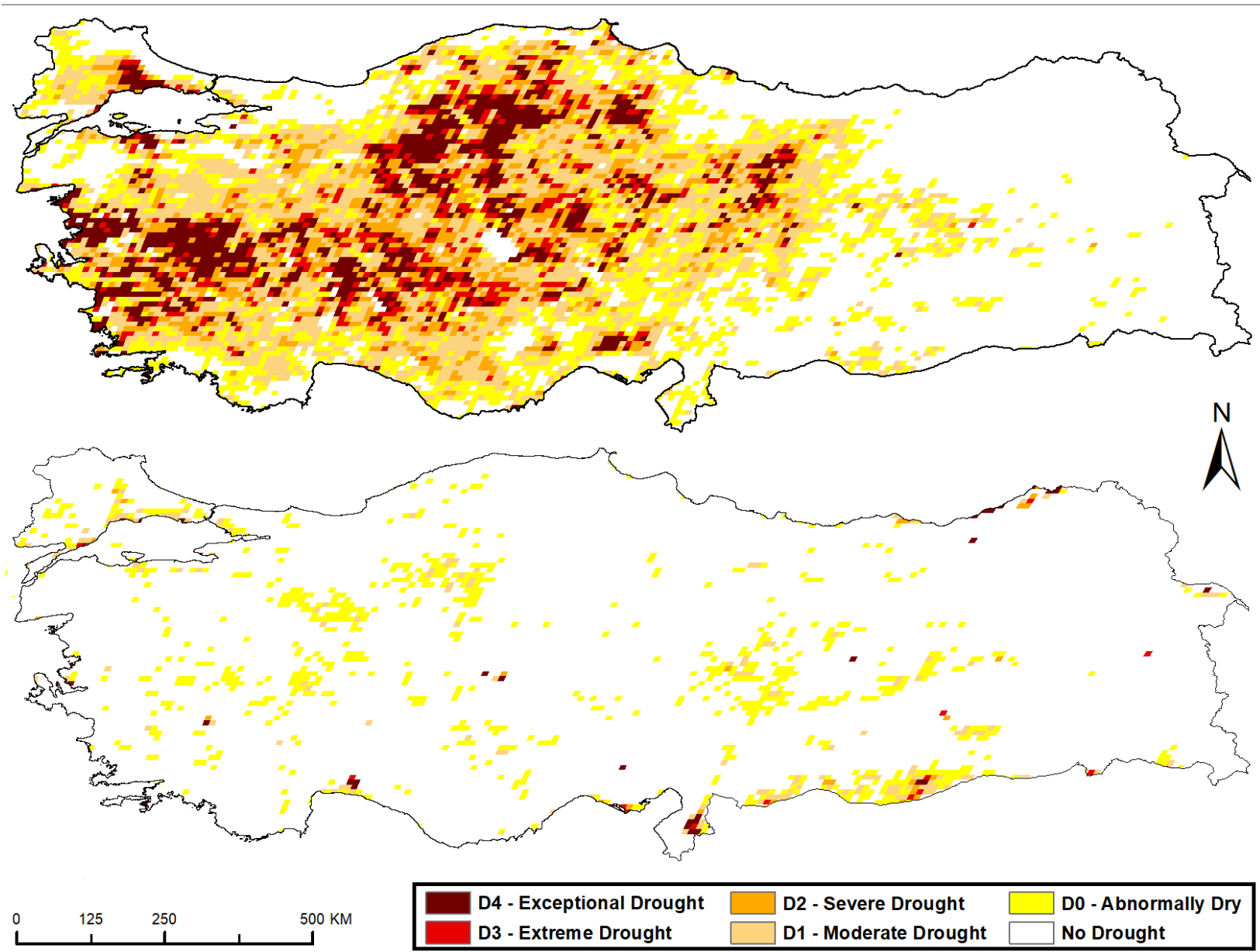

Şekil 3. 11 Temmuz - 27 Temmuz tarih aralığı için 2007 ve 2009 yılları Türkiye Kuraklık Haritaları.

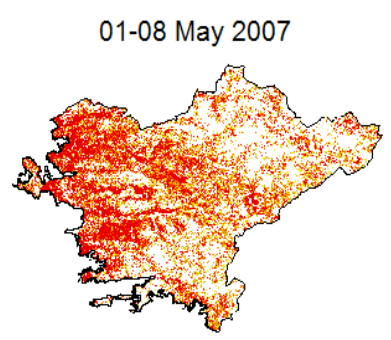

01-08 May 2009

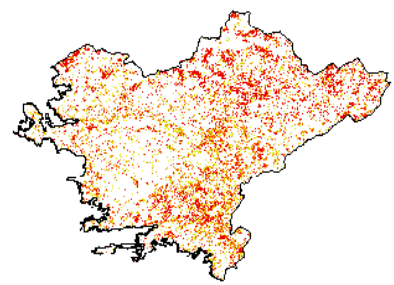

09-16 May 2007

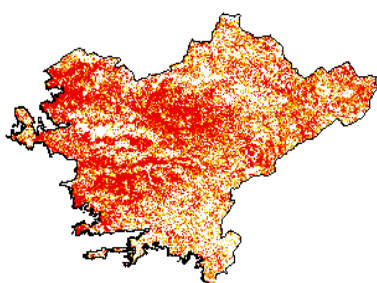

09-16 May 2009
17-24 May 2007

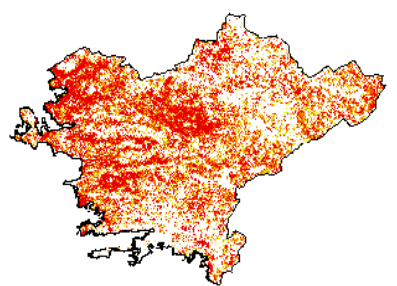

17-24 May 2009
25-31 May 2007

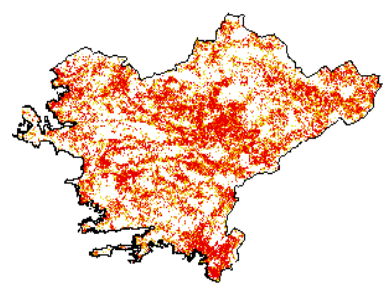

25-31 May 2009
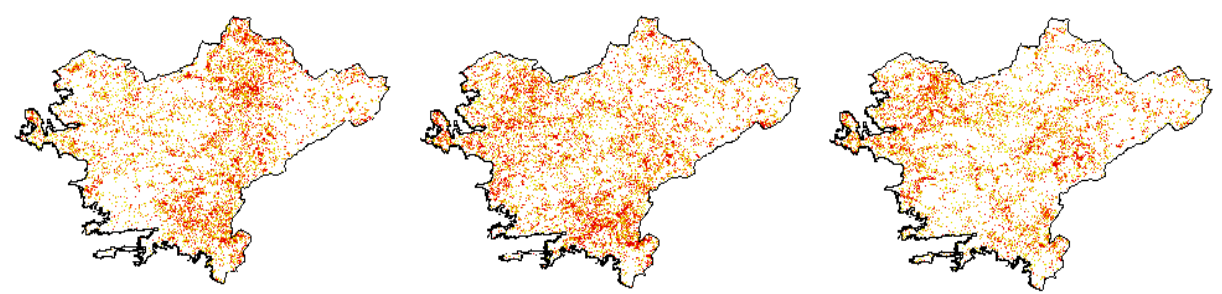

VCI DROUGHT SCALE

\section{Extreme}

Severe

Moderate

Mild

Şekil 4. 2007 ve 2009 yılları Türkiye Ege Bölgesi için Tarımsal Kuraklık Haritaları (Yagci et al. 2011). 


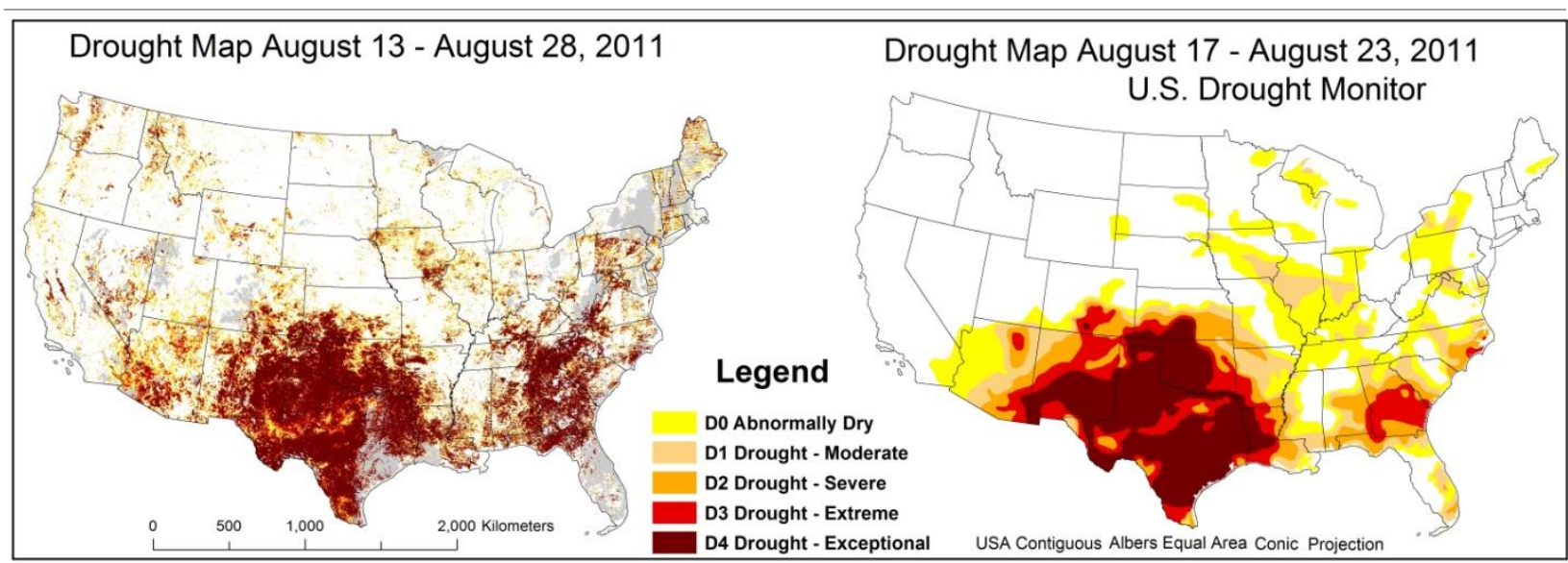

Şekil 5. VCI-tabanlı tarımsal kuraklık haritası (solda) ve Amerikan Kuraklık İzleme Dairesi'nin (United States Drought Monitor, USDM) kuraklık haritası (Sağda) (Deng et al. 2013).

\section{SONUC}

VCI kuraklık indeksinin dünyanın birçok yerinde yapılan çalışamalarda, tarımsal kuraklığı başarılı bir şekilde saptamış olduğu belirtilmiştir (Deng et al. 2013; Yagci et al. 2012; Yagci et al. 2011; Kogan 1995). Bu çalışmalara paralel olarak bu indeks 2007 yılındaki Türkiye'deki ve 2011 yılındaki ABD'deki tarımsal kuraklığın izlenmesi için seçilmiştir. 2007 yılında üzüm veriminde çok büyük düşüş yaşanmıştır. VCI-tabanlı haritalar bu bölgede şiddetli bir kuraklık olduğunu doğru olarak göstermiştir. ABD'deki çalışmada ise bu indeksten üretilen harita, yaygın şekilde kullanılan USDM kuraklık haritası ile mekânsal kapsam ve şiddet olarak çok iyi uyuşmaktadır. Bu çalışmaların paralelinde, bu indeks ülkemizde gerçekleşmiş kuraklık yıllarını belirlemede kullanılabilir. Aynı zamanda güncel olarak kuraklığın izlenmesinde de kullanılabilir.

\section{TEŞEKKÜR}

$\mathrm{Bu}$ çalışmalara katkıda bulunan, George Mason Üniversitesindeki Center for Spatial Information Science and Systems (CSISS) adlı araştırma merkezinden Liping Di, Meixia Deng, Weiguo Han ve Chunming Peng ve mali katkılarından dolayı George Mason Üniversitesine teşekkürü borç bilirim.

\section{KAYNAKLAR}

American Meteorological Society. 2013. Drought. An Information Statement. American Meteorological Society. https://www.ametsoc.org/index.cfm/ams/about-ams/ams-statements/statements-of-the-ams-in-force/drought/.

Deng, Meixia, Liping Di, Weiguo Han, Ali Levent Yagci, Chunming Peng, and Gil Heo. 2013. "Web-ServiceBased Monitoring and Analysis of Global Agricultural Drought." Photogrammetric Engineering \& Remote Sensing 79 (10): 929-943. doi:10.14358/PERS.79.10.929.

Kogan, F. 1993. "Development of Global Drought-Watch System Using NOAA/AVHRR Data.” Advances in Space Research 13 (5): 219-222. doi:10.1016/0273-1177(93)90548-P.

Kogan, F. 1995. "Application of Vegetation Index and Brightness Temperature for Drought Detection." Advances in Space Research 15 (11): 91-100. doi:10.1016/0273-1177(95)00079-T.

Svoboda, Mark, Doug Lecomte, Mike Hayes, Richard Heim, Karin Gleason, Jim Angel, Brad Rippey, et al. 2002. "The Drought Monitor." Bulletin of the American Meteorological Society 83 (8): 1181-1190. doi:10.1175/1520-0477(2002)083<1181:TDM>2.3.CO;2.

The National Drought Mitigation Center. 2016. "Drought Severity Classification." United States Drought Monitor. http://droughtmonitor.unl.edu/AboutUSDM/DroughtClassification.aspx.

Wilhite, Donald A. 2000. "Drought as a Natural Hazard: Concepts and Definitions." In Drought: A Global Assessment, edited by Donald A. Wilhite, 1st ed., 3-18. Hazards and Disasters. London: Routledge.

Yagci, Ali Levent, Liping Di, Meixia Deng, Weiguo Han, and Chunming Peng. 2011. "Vegetation Index Based Technique for Global Agricultural Drought Monitoring." In 5th International Conference on Recent Advances in Space Technologies - RAST, 137-141. Istanbul, Turkey: IEEE. doi:10.1109/RAST.2011.5966808. 
A.L.Yağcı: Uzaktan Algılama Görüntülerinden Tarımsal Kuraklığın Belirlenmesi

Yagci, Ali Levent, Liping Di, Meixia Deng, Genong Yu, and Chunming Peng. 2012. "Global Agricultural Drought Mapping: Results for the Year 2011.” In IEEE International Geoscience and Remote Sensing Symposium, 3764-3767. Munich, Germany: IEEE. doi:10.1109/IGARSS.2012.6350498. 